\title{
Analysis of Teaching Methodologies for Electronics in Non-Specialized Engineering Studies
}

\author{
Y. Lechuga, M. Martinez, R. Casanueva \\ Electronics Technology, Systems and Automation Engineering Department (TEISA) \\ University of Cantabria \\ Santander, Spain \\ \{yolanda, martinez, charo\}@teisa.unican.es
}

\begin{abstract}
Since the academic year 2011-2012, the Electronics courses have started to be taught within the curriculum of the new Degree in Mechanical Engineering and the new Degree in Electrical Engineering, which are part of the undergraduate academic offer of the University of Cantabria (Spain). Both courses follow a common teaching and learning methodology regarding, not only the syllabus contents and organization, but also the assessment of competencies. During four academic years, changes in the course syllabus have been done, as well as different assessment procedures have been developed and analysed. In this way, the teachers of these two courses have been able to evaluate the extent to which students have acquired the expected competencies and also to draw conclusions about the most suited learning methodology to both student profiles, with the specific objective of decreasing the dropout rate.
\end{abstract}

Keywords- Mechanical engineering, electrical engineering, bachelor degree, EHEA, electronics course.

\section{INTRODUCTION}

A graduate in Electrical or Mechanical Engineering is a specialized professional who must have scientific and technical knowledge about generation, transport and distribution of electric energy, or mechanics, respectively, as well as about economics and business management. These bachelor degrees gather the professional attributions of the old Industrial Technical Engineers, with their specializations in Mechanical and Electrical Engineering, as established in the Order CIN/351/2009 [1].

The academic education of Electrical and Mechanical Engineers requires to include, in one hand, common knowledge to all the industrial branches of engineering and, on the other hand, specific knowledge about electric technology and mechanics, respectively. Additionally, the European Higher Education Area, framed within the context of the Bolonia Process [2], implies a new way of teaching and learning based on competencies.

In this sense, courses G740 and G858, both of them called "Electronics" are included in the curriculum of the bachelor degrees in Mechanical and Electrical Engineering, respectively, offered by the University of Cantabria, in order to cover the competency "achievement of the basic knowledge of electronics", which is common to the industrial branch degrees. Both courses share contents, general and common-to industrial-branch competencies, objectives and structure. Both are taught during the second semester of the second year of studies [3,4], and are assigned to the Electronics Technology, Systems and Automation Engineering Department (TEISA) at the University of Cantabria.

Therefore, it is a subject that is not technology-specific of the studies, and the students tend to have a relatively poor motivation towards its study. That fact, together with a widespread lack of knowledge about what Electronics actually entails, make dropout and low attendance an important thread to the success of these courses. For that reason, the teachers of these subjects have developed a four-year analysis of the dropout rate and academic results versus several modifications in the syllabus and assessment method that were carried out and summarized in this work.

Section II of this paper describes the teaching methods, the distance-learning resources, and the assessment method used in a common way during the four academic years. Section III is centred in the evolution of the courses and the actions taken to decrease the dropout rate and to increase attendance and, thus, the students' success in acquiring the expected competencies. Finally, conclusions are presented.

\section{TEACHING Methods, RESOURCES AND ASSESSMENT}

The organizational modalities used in the University of Cantabria so that the students can acquire the competencies set out by the different courses, are categorized into two groups: presence or non-presence activities. Both Electronics courses have established the same distribution for the aforementioned activities, which can be seen in Table I.

\section{A. Theory Lessons}

The "chalk and talk" method, also called "master class" is a traditional methodology that, properly used, can be intended to meet certain purposes such as: introducing a topic, pointing the most appropriate working lines, clarifying conceptual schemes that can be difficult to assimilate, or just motivating.

The distribution shown in Table I establishes 30 hours of theory lessons, which means, considering a total amount of 15 weeks per semester, two hours per week. 
TABLE I. DISTRIBUTION OF COURSE HOURS ACCORDING TO THE ORGANIZATIONAL MODALITIES FOR BOTH COURSES OF ELECTRONICS

\begin{tabular}{c|c} 
Organizational Modalities & Course Hours \\
\hline Presence Activities & \\
\hline Theory Lessons & 30 \\
\hline Practice in classroom & 15 \\
\hline Laboratory work & 15 \\
\hline Follow-up Activities & \\
\hline Tutoring & 9 \\
\hline Evaluation & 6 \\
\hline Total for presence activities & 75 \\
\hline Non-presence Activities & \\
\hline Group work & 30 \\
\hline Individual work & 45 \\
\hline Total for non-presence activities & 75
\end{tabular}

Two important aspects to highlight regarding teaching these two courses, are "coordination" and "timing". We are talking about the same contents (Table II) with the same structure but with different timetable and, more importantly, different actors, regarding, not only the audience, but also the teachers. For example, we give our students with time restrictions the chance to follow the theory and/or problems lessons with one group or with the other, since the coordination between teachers is remarkable, taking into account that not everybody assimilate concepts at the same speed. This facility is very demandable for the teachers of the courses in terms of previous work, organization, and continuous coordination meetings.

Lessons in the Higher Technical School of Industrial and Telecomunication Engineers last 50 minutes. However, several studies have demonstrated that 25 minutes is a reasonable limit for paying attention during class [5]. Due to that, theory lessons often include some rest time in the form of questions to the audience that help to break up the pace.

The resources used for theory lessons are, alternatively, the blackboard and a multimedia presentation with a computer and a projector. Besides that, students always have in advance a copy of the material used, normally the presentation slides, that they can complete in class with their own notes.

\section{B. Practice in classroom or problem lessons}

Problem lessons (1 hour per week) have been conceived as a complement to theory lessons as they have proven to be essential to electronics teaching. Their main purpose is to strengthen the concepts learned during theory lessons and, at the same time, they encourage the analytic and synthetic capabilities of the students. The teacher responsible for these lessons is different from the one for theory lessons, in such a way that the students realize that there is not just one valid way to solve a problem, whether in class or in real life. If reasoning is correct and applicable, it is possible to come to the same result, even through different ways. Besides, critical thinking is encouraged, as the student compares, decides and combines techniques according to his/her own line of thought.
TABLE III.

SYLLABUS

\begin{tabular}{l|c}
\multicolumn{1}{c|}{ CONTENTS } & Week \\
\hline $\begin{array}{l}\text { Basic laws of electronic circuits: Ohm's and Kirchoff's laws, passive } \\
\text { components, association, voltage and current dividers }\end{array}$ & 1 \\
\hline Digital Electronics: Digital vs. Analog, Combinational Logic & 1 - \\
\hline $\begin{array}{l}\text { Introduction to semiconductors and active devices: diodes and } \\
\text { MOS transistors }\end{array}$ & 5 - 7 \\
\hline Sequential Logic: components, analysis & 8 - 9 \\
\hline MOS Amplifiers: biasing, basic discrete single-stage configurations & 10 - 11 \\
\hline $\begin{array}{l}\text { Operational Amplifiers: ideal and real model, linear and non-linear } \\
\text { applications, limitations }\end{array}$ & 12 - 13 \\
\hline Circuits with diodes & 14 \\
\hline Filters and data converters & 15
\end{tabular}

In these classes the teacher usually solves the problem using the blackboard, while trying to think out loud, pointing out the steps taken and the pursued goals, as if the teacher were the student.

Besides that, teachers recommend using symbolic data until a result is obtained, to substitute symbols and variables by their numerical values at the end, expressing them in their correct units, and highlighting the importance of dimensional analysis for verification.

\section{Laboratory work}

Practice in a laboratory is a fundamental part of the teaching-learning process for technical studies, and thus, for Electronics. Our laboratory entails the students' first contact with real electronics systems and specific instrumentation and, therefore, it offers the student a way to prove experimentally the concepts introduced in class, and also to observe the difference between theoretical calculations and experimental results.

Depending on the goals of each practical session, the proposed work can be oriented towards analysis (predetermined experimental setup) or towards synthesis (a set of specifications is demanded and the student must design a circuit that fulfil them). Considering the characteristics rather general of these courses, most of the proposed exercises are of the analysis type, although some aspects about synthesis are included in the laboratory program to complement the students' training and also to provide them a view of what electronics design can entail.

During the laboratory sessions, the students normally work in groups of two persons, following a teaching method of intrinsic cooperative work that permits the acquisition of, not only technical and methodological competencies, but also social and participatory ones, demanded by the European Higher Education Area (EHEA).

Students are encouraged to take notes on all the data that they measure, as well as every incidence they face. All this information is the starting point to write, afterwards, a report about the exercises developed in the laboratory. In spite of the extra work it implies for the students, a proper presentation of the work done is crucial for their future professional activity.

While the practice session takes place, the teacher is always available to solve any doubt, and also to observe students' 
performance with the intention of considering it in the on-going assessment.

It is important to coordinate the laboratory sessions with the presence activities in the classroom, especially, the theory lessons, in order to have previously introduced the basic concepts needed for the correct development of the practice. In this sense, the students always dispose of the practical guides in advance, so that they can prepare them adequately.

\section{Distance-learning resources}

The "Virtual Classroom" of the University of Cantabria uses two different platforms: Blackboard and Moodle; but both with a similar structure and features, for distance teaching through Internet. The access to both platforms is limited to the teachers of the course and the students officially enrolled in them. In the particular case of courses G740 and G858, the platform that has been chosen for distance-learning is Moodle, and the contents included in the virtual course are, for example, but not limited to: theory presentations, work sheets, problems, laboratory guides, data sheets and characteristics for different devices, evaluation results, previous written exams, discussion and news forums, etc.

\section{E. Assessment}

The evaluation task permits the teachers of the course to obtain a measurement of the achievement of competencies reached by the students, and also important information about the efficiency of the procedure.

On-going assessment is the evaluation method that more clearly permits to follow the students' assimilation process. This type of assessment forces the students to work more regularly on certain aspects and contents of the course that, otherwise, would be postponed for the benefit of "more pressing tasks". In the case of courses G740 and G858 ongoing assessment is applied to laboratory sessions, and also to theory lessons through written partial exams that take place after a certain topic or related topics are explained, or at the middle of the semester.

Among the variety of exams that can be done, in these courses we have opted for written exams that include short questions and problems because of their benefits: common base for correction, objectivity, documentary prove if revision is needed, and application of decision-making and analysis and synthesis capabilities during the resolution of problems.

As far as the laboratory assessment is concerned, it is basically based on notes taken during the lab sessions about the students' performance, the accomplishment of the previous theoretical calculations, and the final report summarizing the laboratory work done.

\section{EVOLUTION AND RESULTS}

One of the worrying issues regarding the relative success of the courses is the "dropout rate". This becomes especially important in courses like these, which deal with topics not directly related to the engineering specialization.

During the first academic year (2011-2012) the syllabus started with an introduction about semiconductors to continue afterwards with basic analog electronics and finally with basic digital electronics. As far as the evaluation process followed is concerned, only $40 \%$ of the mean score was assigned to the final written exam in June, whereas the other 60\% was equally assigned to both the laboratory and the on-going assessment. This last evaluation method consisted in four written exams carried out during the semester where the topics of the course were consistently divided and the assimilation of the concepts separately appraised. Two mean scores were calculated: one considering the aforementioned method, and other not taking into account the on-going assessment (only laboratory and final exam marks $30 \%+70 \%$ ). The most beneficial result for the student was selected.

However, the dropout rate, regarding the number of students enrolled in the course (44 for G740 and 6 for G858), was considered excessive, and changes for the next academic year were proposed.

Fig 1 and Fig. 2 show the dropout rate for the on-going assessment during the four academic years analysed, discriminating the moment such $\mathrm{d}$ took place: early halfway or final, depending on the exam where it was detected (the first, the second or the last one).

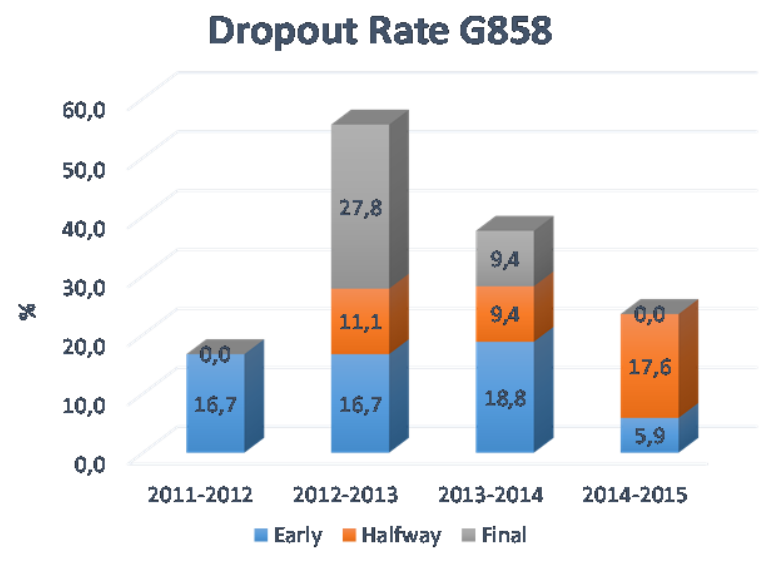

Fig. 2. Dropout rate for the course G858- Electronics 
After some discussion, students' motivation was identified to be possibly responsible for such an early dropout and the evaluation method was modified in order to increase students' participation in the on-going assessment process. In this sense, both the final exam and the on-going assessment had the same weight in the mean score, in such a way that if a student overcame the on-going assessment by getting an average grade higher than a five, it wasn't needed to take the final exam in June. That initiative had a good reception by the students and early dropout was reduced.

Nevertheless, and quite surprisingly, the overall dropout rate increased significantly. For the particular case of the mechanical studies, students' enrolment in the course almost doubled (from 48 to 78), which made the follow-up of how the concepts where assimilated a difficult task. However, from the data obtained by students' feedback, those concepts related to semiconductors and analog circuits were proven to be the most difficult ones for them to assimilate, as they lost sight of the big picture by focusing in the device and the circuit. They lost their initial motivation by facing hard-tounderstand devices and circuits without seeing the application and the role played by these circuits in complex analog and mixed-signal systems.

As shown in Fig. 1, dropout rate increased more than $24 \%$ after the first exam of the on-going assessment. That first exam included topics such as semiconductors, n-type and p-type doping, p-n junction, diodes and simple circuits with diodes. As shown in Fig. 2, this dropout appeared later, but was equally unacceptable. The academic results were bad for the first two exams and many students decided to abandon the on-going assessment although the teachers insisted that it was still possible to overcome it if the following results compensate the previous ones.

After this experience, the order of the topics was modified in such a way that the theory of semiconductors was introduced after combinational logic was explained (Table II), so that the students could understand better the behaviour of logic gates, and analog circuits were explained after the digital part of the course was finished. In this way, the level of complexity was low at the beginning and, when more difficult topics were introduced, the students had had enough time to get used to the new vocabulary, methodology and tools. Besides that, basic digital concepts, with its higher level of abstraction, kept, to some extent, that big-picture sight of a system.

As shown again in Fig. 1 and Fig. 2, during year 20132014, dropout rate suffered an important decrease. However, after analyzing the results of the exams individually, we realized that some of them were worse, even if the topics had proven to be easily assimilated in previous years. When questioned about it, the students admitted that they had not dedicated much time to study Electronics since these exams coincided in time with other exams or deadlines that, according to them, were "more important" or "more demanding”.

Because of this, in the year 2014-2015 another approach, more in accordance with the students' demand of less overload of exams, was implemented. Now only a midterm written exam was done, including the digital and semiconductor topics and, if the student overcame it, the final exam in June would only include the remaining analog part. In this case, Fig. 1 and Fig. 2 consider as early dropout the students that never came to the laboratory sessions, although they require compulsory attendance, and halfway dropout the one detected at the midterm exam. As it can be seen, the overall dropout rate has decreased again but at the expense of worse academic results and less class attendance.

In order to improve these two aspects, especially the attendance-related one, the teachers plan to go back to the initial scheme of $30 \%+30 \%+40 \%$, but substituting the exams during the semester by a more faithful interpretation of an on-going assessment. This will consist of short exercises and questions that could be solved individually or in groups, in class or at home, and that can take place, for example, once a week, or even any day during class time. This part of the evaluation won't be recoverable thus increasing the student's commitment with the principles of on-going assessment and also the perceived importance of class attendance. This approach will undoubtedly increase teacher's workload. Nonetheless, we expect to compensate it with higher assistance rates that will surely entail better academic results and less dropout.

\section{CONCLUSIONS}

In this work, the implantation of two Electronics courses for non-specialized studies have been analysed. In this type of subjects, dropout and low attendance are worrying issues that have been included in the analysis.

In other to decrease the dropout rate and to increase class attendance several proposals for changes have been implemented with satisfactory results in most of the cases. Two of these proposals deserve to be highlighted: the variation in the order in which the contents of the course are explained, and the different approaches carried out to motivate students to participate in the on-going assessment process.

According to the results obtained, new proposals for next year were also presented.

\section{REFERENCES}

[1] Orden CIN/351/2009, del 9 de febrero de 2009, BOE Boletin Oficial del Estado, n44, viernes 20 de febrero de 2009. Available on: http://www.boe.es/boe/dias/2009/02/20/pdfs/BOE-A-2009-2893.pdf

[2] The Bologna Declaraten of 19 June 1999, Joint declaraten of the European Ministers of Education. Available on: http://www.ehea.info/Uploads/Declaratens/BOLOGNA_DECLARAT EN1.pdf

[3] Memoria para la solicitud de verificación de títulos oficiales. Propueta de título de Grado en Ingerniería Eléctrica. Available on: http://web.unican.es/estudios/Documents/DOT/MET-GELECTRICA.pdf

[4] Memoria para la solicitud de verificación de títulos oficiales. Propueta de título de Grado en Ingerniería Mecánica. Available on: http://web.unican.es/estudios/Documents/DOT/MET-GMECANICA.pdf

[5] W.J. McKeachie, M. Svinicki, "McKeachie's teaching tips: Strategies, research, and theory for college and university teachers", Ed. Houghton Mifflin Company, 2006. 